\title{
Distribution and relative abundance of flyingfish (Exocoetidae) in the eastern Caribbean. III. Juveniles
}

\author{
Hazel A. Oxenford ${ }^{1}$, Robin Mahon ${ }^{2}$, Wayne Hunte ${ }^{1,2}$ \\ ${ }^{1}$ Marine Resource and Environmental Management Programme (MAREMP), University of the West Indies, Cave Hill, Barbados \\ ${ }^{2}$ Bellairs Research Institute of McGill University, St. James, Barbados
}

\begin{abstract}
We investigated the distribution and abundance of juvenile flyingfish in the eastern Caribbean by nightlighting and dipnetting at 20 stations from April 10 to May 6, 1988. Of the 2211 fish collected, $73.5 \%$ were flyingfish. Abundance of juvenile flyingfish varied significantly across the survey area, but was not correlated with any of the surface water characteristics measured (salinity, temperature, $\mathrm{PO}_{4}-\mathrm{P}, \mathrm{NO}_{3}-\mathrm{NO}_{2}-\mathrm{N}$ ), nor with flotsam abundance or moon phase. Parexocoetus brachypterus (49.5\%), Exocoetus volitans ( $41.0 \%)$ and Hirundichthys affinis ( $8.0 \%$ ) accounted for $98.5 \%$ of the flyingfish catch. The length-frequency distribution of $P$. brachypterus was trimodal, the largest size group being adult. The length-frequency distributions of $E$. volitans and $H$. affinis were bimodal. In both cases, the largest size group was adult, but adults of E. volitans were rare, accounting for $<3 \%$ of the E. volitans catch. Abundance of all size groups of all 3 species varied significantly across the survey area, and different life history stages within a species had different geographical distributions. For example, adults of $E$. volitans were virtually absent from the survey area, but larvae and juveniles were common. Variation in abundance of juveniles and adults of $H$. affinis was not correlated across the survey area, and the same was true for small juveniles and adults of $P$. brachypterus. The integrity of sizespecific geographical distributions is supported by the fact that different survey methods typically detected the same geographical distributions for similar life history stages. Abundance of $P$. brachypterus larvae in neuston tows was correlated with abundance of the smaller juvenile size group of $P$. brachypterus sampled by nightlighting. Abundance of $E$, volitans larvae in neuston tows was correlated with abundance of $E$. volitans juveniles taken by nightlighting, and abundance of $H$. affinis adults detected by visual survey was correlated with their abundance in nightlighting samples.
\end{abstract}

KEY WORDS: Flyingfish · Juveniles · Dipnet survey · Nightlighting · Eastern Caribbean

\section{INTRODUCTION}

Flyingfish (Exocoetidae) are a common and commercially important component of the eastern Caribbean pelagic fish fauna (Oxenford et al. 1993), but there is little information on the regional distribution of any life history stage for any flyingfish species. The distribution and relative abundance of flyingfish spawning substrata, eggs, larvae and adults in the eastern Caribbean have been investigated by Oxenford et al. (1995, this issue; for adults) and Hunte et al. (1995, this issue; for other life history stages). The visual survey technique used for adults and the neuston tows used for eggs and larvae provide no information on the considerable size range of flyingfish juveniles too large to be captured by neuston tows and too small to be detected by visual surveys. However, flyingfish juveniles in this size range can be aggregated around survey vessels by nightlighting and hence captured by dipnet [see Lewis (1961) for Parexocoetus brachypterus (Gosse) and Lewis et al. (1962) for Hirundichthys affinis (Günther)]. Lao (1989) used this technique to investigate seasonal and spatial variation in abundance and size of juveniles of $H$. affinis, $P$. brachypterus and Exocoetus volitans (Linnaeus) off the northwest coast of Barbados.

The objectives of this study were to investigate the distribution and relative abundance of flyingfish juveniles in the eastern Caribbean by nightlighting and dipnetting, and to compare the data with those ob- 
tained on the distribution and relative abundance of adult (Oxenford et al. 1995) and larval flyingfish (Hunte et al. 1995).

\section{METHODS}

Study area. The distribution and relative abundance of flyingfish juveniles in the eastern Caribbean was surveyed by nightlighting and dipnetting during a 1 mo cruise (April 10 to May 6, 1988) on RV 'Provider', conducted during the period of peak seasonal abundance of adult flyingfish in the region (April to June; Mahon et al. 1986) and the period of peak abundance of flyingfish larvae and juveniles off Barbados (February to June; Lao 1989). A total of 20 nightlighting stations were occupied over the survey area, which covered 67500 square nautical miles $\left(\mathrm{nmi}^{2}\right)$ of the eastern Caribbean, extending from Trinidad in the southeast to Dominica in the north (Fig. 1).

Sampling procedure. Nightlighting was conducted between 19:00 and 03:00 $\mathrm{h}$ at 4 different locations at each of the 20 nightlighting stations. Locations were approximately $0.5 \mathrm{nmi}$ apart, and sampling was con-

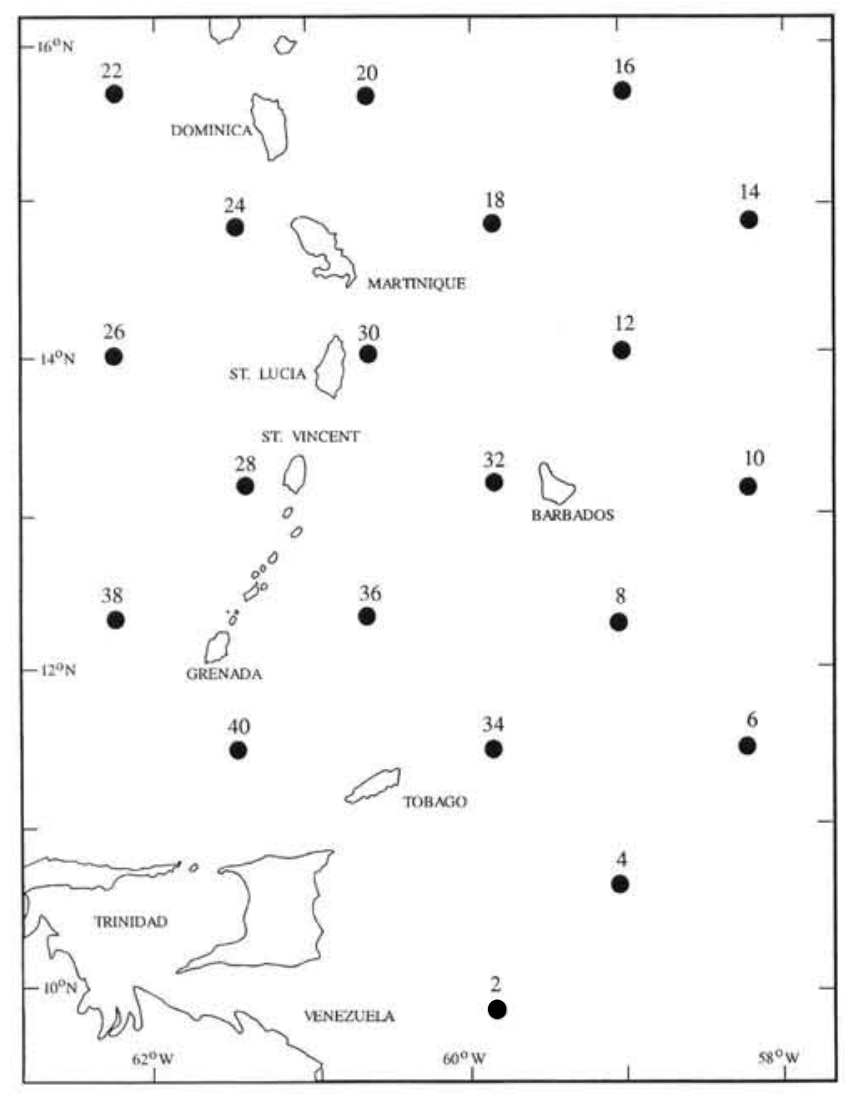

Fig. 1. Area surveyed by nightlighting and dipnetting for juvenile flyingfish, showing the sampling stations ducted for $40 \mathrm{~min}$ at each location, i.e. for a total of $160 \mathrm{~min}$ at each station. We moved between locations to decrease the possibility of a 'depletion effect' due to local over-sampling [see Lao (1989) for an indication that local abundance may decrease by the third hour of nightlight sampling at one location]. To check for depletion over the $40 \mathrm{~min}$ period at each location, data were recorded in 10 min intervals.

To sample, four $200 \mathrm{~W}$ spot lamps were used to illuminate a zone on the leeward side near the centre of the vessel. Use of the leeward side reduced wave action and facilitated capture. Samplers used longhandled dipnets of $5 \mathrm{~mm}$ mesh size, and worked in pairs, attempting to capture all fish that entered the illuminated zone. The composition of pairs was changed after each 40 min sampling period at each station, to minimise bias resulting from variation in catching skills between samplers. The mean number of flyingfish caught at each of the 4 locations was used as the index of abundance for that station. Squid were occasionally observed to prey on flyingfish in the illuminated zone. Their abundance was therefore monitored to investigate whether they deterred flyingfish from entering the illuminated zone, thereby biasing the abundance index. Squid abundance was monitored by a single observer at a second illuminated position on the leeward side of the vessel, near the stern, by recording all squid entering the illuminated area during each 40 min sampling period. The mean number of squid observed at each of the 4 locations was taken as the index of squid abundance for that station.

Environmental factors. Surface water samples were collected at each sampling station and analysed for temperature, salinity, total reactive phosphorous $\left(\mathrm{PO}_{4}-\mathrm{P}\right)$ and oxidised nitrogen $\left(\mathrm{NO}_{3}-\mathrm{NO}_{2}-\mathrm{N}\right)$, as described by Oxenford et al. (1995). Moon phase was also recorded at each station by coding it from 0 at new moon to 14 at full moon. Cloud cover of the moon was recorded, but occurred during only 3 of 80 sampling periods.

Sample and data treatment. All fish captured were identified as far as possible, and frozen for later sorting and confirmation of species identifications. Flyingfish juveniles were identified to species using the taxonomic descriptions of Breder (1938), Imai $(1959,1960)$, Evans (1961), Lewis (1961), Kovalevskaya (1964) and Lao (1989). During sorting, flyingfish were separated from other families, stored in $5 \%$ buffered formalin, and measured for fork length (FL) to the nearest $\mathrm{mm}$. Modes in length-frequency histograms were clear and could be separated by eye.

All data were tested for normality and homogeneity of variance. The data were not normal and could not be normalised using standard transformations. Nonparametric statistical analyses have therefore been used throughout. 


\section{RESULTS}

\section{Reliability of abundance index}

Using data from all stations (four 10 min sampling periods at each of 4 locations, at each of 20 stations), the mean number of flyingfish caught per $10 \mathrm{~min}$ time interval did not differ significantly between the 4 successive $10 \mathrm{~min}$ intervals (Kruskal-Wallis test: $H=3.503$, $\mathrm{n}=320, \mathrm{p}=0.320$ ), perhaps indicating that depletion through local over-sampling does not occur during the 40 min sampling period conducted at each location. The inability to detect differences between time intervals could result from variation in abundance between stations. However, a non-parametric 2-way ANOVA (Zar 1984) using intervals and stations again indicated no significant difference in flyingfish catch rates between time intervals, and no significant interaction between intervals and stations (for intervals, $H=3.67$, $\mathrm{p}=0.393$; for interaction, $H=30.85, \mathrm{p}=0.867 ; \mathrm{n}=320$ in both cases). This again suggests that depletion through local over-sampling does not occur over a 40 min sampling period, and confirms that depletion effects cannot bias the abundance indices obtained in this survey.

Since no depletion effects were detected, subsequent analyses of abundance are based on the total number of fish caught over the $40 \mathrm{~min}$ sampling period at each location. Moveover, variation in flyingfish

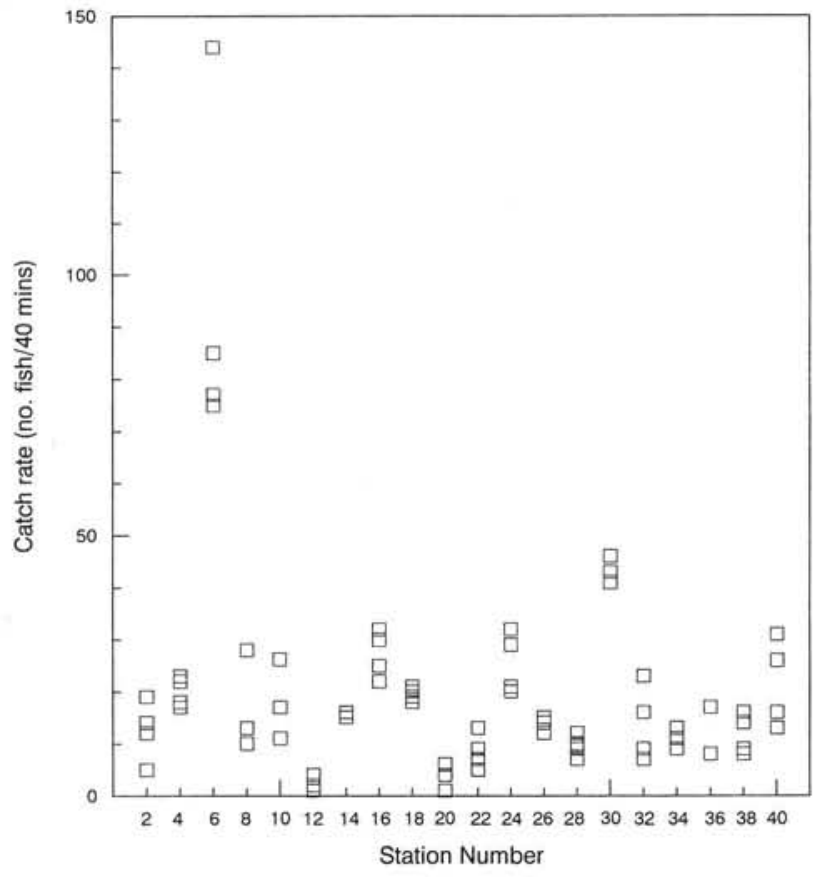

Fig. 2. Within- and between-station variation in catch rates of flyingfish sampled by nightlighting and dipnetting across the survey area. Station positions are shown in Fig. 1 catch rates between the 4 locations at a station was low compared with variation in catch rates between stations (Fig. 2), suggesting that the mean number of flyingfish caught per $40 \mathrm{~min}$ of nightlighting at each station (i.e. mean of 4 locations) is an adequate index for assessing relative abundance of flyingfish between stations.

Mean squid abundance differed significantly between the 20 sampling stations (Kruskal-Wallis test: $H=55.971, \mathrm{n}=80, \mathrm{p}<0.001)$. However, mean flyingfish abundance indices and mean squid abundance indices were not significantly correlated across stations (Spearman rank correlation: $r_{\mathrm{s}}=0.176, \mathrm{n}=20, \mathrm{p}=$ 0.443 ), suggesting that the presence of squid did not deter flyingfish from entering the illuminated sampling zone, and hence did not bias the flyingfish abundance indices obtained in this survey.

\section{Abundance of all juveniles}

A total of 2211 fish comprising at least 12 different families was collected during the approximately $53 \mathrm{~h}$ of nightlighting conducted at the 20 stations (Table 1). Of these, 1625 were flyingfish, with a mean abundance of 20.3 per 40 min nightlighting (Table 2). Flyingfish (Exocoetidae) was therefore the most common family, comprising $73.5 \%$ (by number) of the total catch (Table 1). The relative abundance of the 7 flyingfish species captured is shown in Table 2. The 3 most common species (Parexocoetus brachypterus, Exocoetus volitans and Hirundichthys affinis) accounted for $98.5 \%$ of the flyingfish catch.

Table 1. Abundance, by number and \% frequency of occurrence, of fish families collected by nightlighting and dipnetting at 20 stations (160 min per station) across the survey area in the eastern Caribbean

\begin{tabular}{lrr|}
\hline Family & No. & $\%$ \\
\hline Exocoetidae & 1625 & 73.5 \\
Myctophidae & 230 & 10.4 \\
Hemiramphidae & 201 & 9.1 \\
Coryphaenidae & 62 & 2.8 \\
Belonidae & 15 & 0.7 \\
Holocentridae & 8 & 0.4 \\
Dactylopteridae & 5 & 0.2 \\
Mullidae & 3 & 0.1 \\
Carangidae & 3 & 0.1 \\
Istiophoridae & 3 & 0.1 \\
Balistidae & 2 & 0.1 \\
Monacanthidae & 1 & 0.1 \\
Unidentified & 53 & 2.4 \\
& & \\
All fish & 2211 & 100 \\
\hline
\end{tabular}


Table 2. Abundance, by number, \% frequency of occurrence and abundance index (overall mean number of fish per 40 min nightlighting) of flyingfish species collected by nightlighting and dipnetting at 20 stations (160 min per station) across the survey area

\begin{tabular}{|lrrr|}
\hline Species & No. & $\%$ & $\begin{array}{c}\text { Abundance } \\
\text { index }\end{array}$ \\
\hline Parexocoetus brachypterus & 805 & 49.5 & 10.06 \\
Exocoetus volitans & 670 & 41.2 & 8.38 \\
Hirundichthys affinis & 130 & 8.0 & 1.63 \\
H. speculiger & 12 & 0.8 & 0.15 \\
Cypselurus cyanopterus & 4 & 0.3 & 0.06 \\
C. furcatus & 2 & 0.1 & 0.03 \\
E. obtusirostris & 2 & 0.1 & 0.03 \\
All flyingfish & 1625 & 100 & 20.30 \\
\hline
\end{tabular}

The abundance of flyingfish juveniles differed significantly between stations (Table 3 ; Kruskal-Wallis test: $H=66.028, \mathrm{n}=80, \mathrm{p}<0.001$ ), but there was no obvious geographical pattern to the distribution. Salinity, temperature, $\mathrm{PO}_{4}-\mathrm{P}$ and $\mathrm{NO}_{3}-\mathrm{NO}_{2}-\mathrm{N}$ of surface water differed significantly across the survey area (Oxenford et al. 1995), but none were significantly correlated with abundance of juvenile flyingfish (Spear- man rank correlation: $\mathrm{r}_{\mathrm{s}}<0.311, \mathrm{p}>0.245$ in all cases). Moreover, abundance of juvenile flyingfish was not correlated with either moon phase (Spearman rank correlation: $\left.\mathrm{r}_{\mathrm{s}}=-0.179, \mathrm{n}=20, \mathrm{p}=0.434\right)$, or with flotsam abundance taken by neuston tows (Hunte et al. 1995 ) at the same sampling stations (Spearman rank correlation: $r_{\mathrm{s}}=-0.229, \mathrm{n}=20, \mathrm{p}=0.319$ ).

\section{Parexocoetus brachypterus}

A total of 805 specimens of Parexocoetus brachypterus with a mean abundance of 10.06 fish per $40 \mathrm{~min}$ nightlighting was collected at the 20 stations over the survey area (Table 2). The length-frequency distribution was trimodal, the smallest size group having a mean length of $42.9 \mathrm{~mm} \mathrm{FL}$, the second $84.0 \mathrm{~mm} \mathrm{FL}$, and the largest $117.8 \mathrm{~mm}$ FL (Fig. 3). P. brachypterus reaches sexual maturity at about 110 to $120 \mathrm{~mm}$ (Bruun 1935, Lewis 1961). The largest size group is, therefore, referred to as adult and the smaller size groups as juveniles in this study.

Abundance of both juveniles and adults of Parexocoetus brachypterus varied significantly between stations (Table 3; Kruskal-Wallis tests: for small juveniles, $H=50.643$; for large juveniles, $H=56.467$; for adults, $H$

Table 3. Abundance (mean number of fish per 40 min nightlighting) of flyingfish collected by nightlighting and dipnetting over the survey area, presented separately by station for all flyingfish and for the more common species (Parexocoetus brachypterus, Exocoetus volitans and Hirundichthys affinis). Station positions are shown in Fig. 1

\begin{tabular}{|c|c|c|c|c|c|c|c|}
\hline \multirow{2}{*}{$\begin{array}{l}\text { Stn } \\
\text { no. }\end{array}$} & \multirow{2}{*}{$\begin{array}{c}\text { All } \\
\text { flyingfish }\end{array}$} & \multicolumn{3}{|c|}{ - P. brachypterus } & \multirow{2}{*}{$\begin{array}{l}\text { E. volitans } \\
\text { Juveniles }\end{array}$} & \multicolumn{2}{|c|}{ H. affinis } \\
\hline & & $\begin{array}{c}\text { Small } \\
\text { juveniles }\end{array}$ & $\begin{array}{c}\text { Large } \\
\text { juveniles }\end{array}$ & Adults & & Juveniles & Adults \\
\hline 2 & 12.50 & 0.75 & 0.25 & 8.25 & 0.75 & 1 & 1 \\
\hline 4 & 20 & 2 & 0.75 & 3 & 11.50 & 0.25 & 0 \\
\hline 6 & 95.25 & 2 & 10.25 & 68 & 12.50 & 1 & 0 \\
\hline 8 & 21.75 & 2.25 & 0.75 & 3.50 & 13.25 & 1.50 & 0 \\
\hline 10 & 17.75 & 0.25 & 7.50 & 0.25 & 7.25 & 1.25 & 0 \\
\hline 12 & 2 & 0 & 0.50 & 0.25 & 1.25 & 0 & 0 \\
\hline 14 & 15.50 & 0 & 6.50 & 1.25 & 6 & 0 & 0 \\
\hline 16 & 27.25 & 0.50 & 1.25 & 0.25 & 24.50 & 1 & 0 \\
\hline 18 & 19.50 & 0.50 & 5.25 & 7.50 & 4.50 & 0 & 0.75 \\
\hline 20 & 3 & 0 & 0 & 0 & 2.50 & 0.50 & 0 \\
\hline 22 & 8.50 & 1 & 0 & 0.75 & 3.50 & 0.75 & 1.25 \\
\hline 24 & 25.50 & 2 & 0 & 0 & 22 & 0.50 & 0.50 \\
\hline 26 & 13.25 & 0.75 & 1.50 & 1.50 & 8.75 & 0.50 & 0.50 \\
\hline 28 & 9.50 & 2 & 0.75 & 1.75 & 0 & 0.75 & 0.25 \\
\hline 30 & 42.75 & 2.50 & 0 & 0 & 36.25 & 0.50 & 0 \\
\hline 32 & 13.75 & 1.75 & 0.75 & 0.25 & 9.25 & 0.75 & 0 \\
\hline 34 & 10.50 & 5 & 0.25 & 1 & 3.50 & 1 & 0.25 \\
\hline 36 & 14.75 & 4.75 & 0.75 & 1.50 & 0 & 4.75 & 0 \\
\hline 38 & 11.75 & 4.25 & 2.50 & 1.50 & 0.25 & 1.75 & 0.25 \\
\hline 40 & 21.50 & 0.25 & 1.75 & 14.50 & 0 & 3.75 & 0 \\
\hline $\begin{array}{l}\text { Overall } \\
\text { mean }\end{array}$ & 20.30 & 1.63 & 2.06 & 5.75 & 8.38 & 1.08 & 0.24 \\
\hline
\end{tabular}




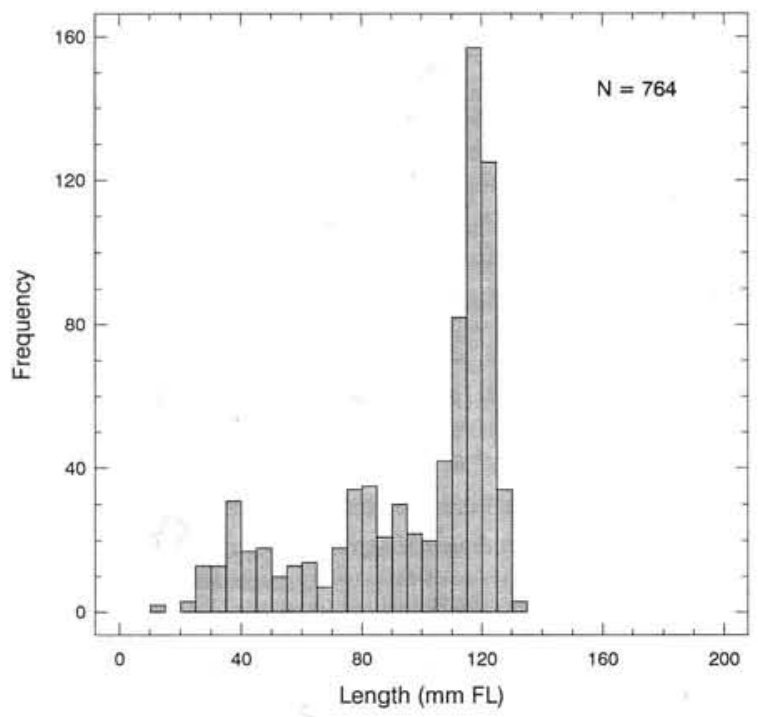

Fig. 3. Parexocoetus brachypterus. Length ( $\mathrm{mm}$ fork length, FL) distribution of juveniles collected by nightlighting and dipnetting across the survey area

$=58.901 ; \mathrm{p}<0.001$ and $\mathrm{n}=80$ in all cases). The abundance of small juveniles was not significantly correlated with either that of large juveniles or adults, but the abundance of large juveniles was significantly correlated with that of adults (Spearman rank correlation: for small juveniles vs large juveniles, $r_{s}=-0.210, p=$ 0.360 ; for small juveniles vs adults, $\mathrm{r}_{\mathrm{s}}=0.129, \mathrm{p}=0.575$; for large juveniles vs adults, $\mathrm{r}_{\mathrm{s}}=0.509, \mathrm{p}=0.027 ; \mathrm{n}=20$ in both cases). There was no obvious geographical pattern to the variation in abundance of the smaller juveniles (mean $42.9 \mathrm{~mm}$ FL), although abundance appeared to be lower in the northeastern sector of the survey area than in more southern sectors, and no obvious geographical pattern to the variation in abundance of the larger juvenile size group (mean $84.0 \mathrm{~mm}$ FL), although abundance appeared to be lower in the northwestern sector of the survey area (Fig. 4). Interestingly, the variation between stations in abundance of $P$. brachypterus larvae as determined by neuston tows (mean length $34.5 \mathrm{~mm}$ FL; Hunte et al. 1995) was significantly correlated with the variation in abundance of the smaller size group of juveniles taken by the dipnet (mean length $42.9 \mathrm{~mm}$ FL; Spearman rank correlation: $r_{s}=0.699, n=20, p<0.002$ ), but not with the larger size group of the juveniles taken by the dipnet (mean length $84.0 \mathrm{~mm}$ FL; Spearman rank correlation: $\mathrm{r}_{\mathrm{s}}=0.029, \mathrm{n}=20, \mathrm{p}=0.899$ ). The adults of $P$. brachypterus were most abundant east of Barbados and Tobago, an area in which visual surveys also detected high abundance (Oxenford et al. 1995). However, the correlation between adult abundance as indicated by dipnet and abundance as detected by visual

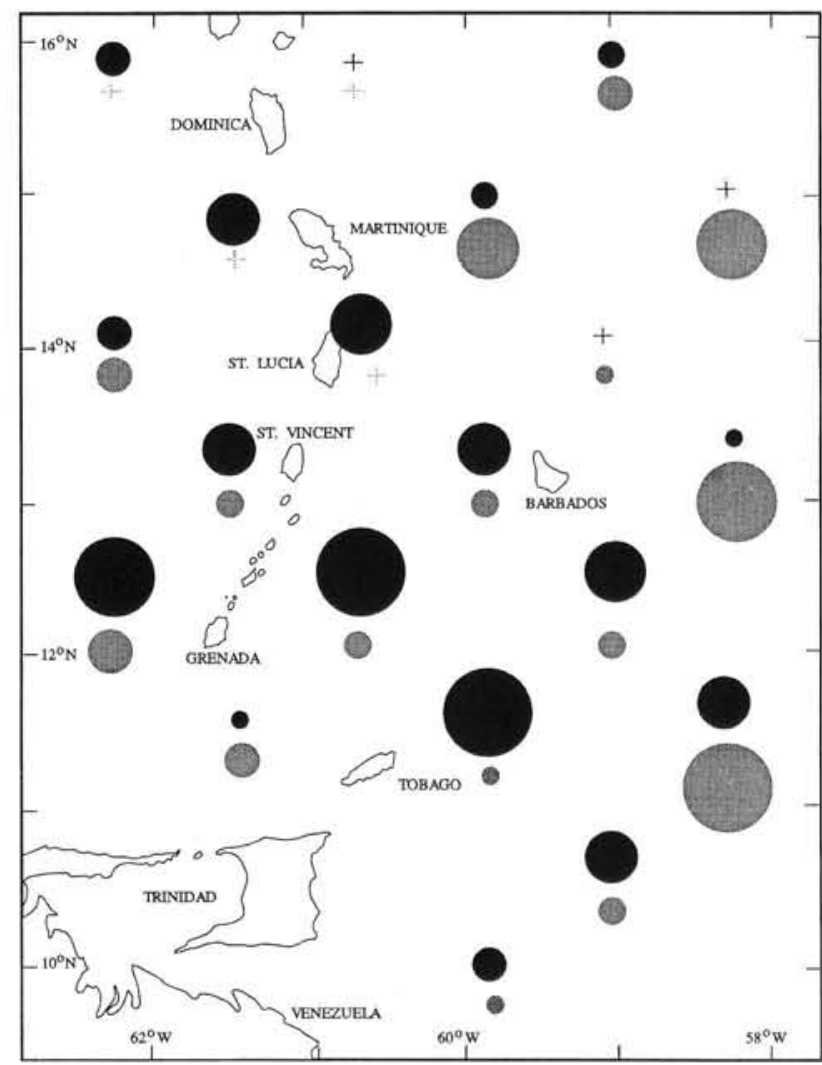

Fig. 4. Parexocoetus brachypterus. Relative abundance of (-) small juveniles (mean length $42.9 \mathrm{~mm}$ FL) and of (๑) large juveniles (mean length $84.0 \mathrm{~mm}$ FL) collected by nightlighting and dipnetting across the survey area. Area of circle is proportional to the mean abundance (range for small juveniles is 0 to 4.75 fish per 40 min nightlighting; range for large juveniles is 0 to 10.25 fish per 40 min nightlighting). $(+/+)$ station without small/large $P$. brachypterus

survey was not statistically significant across the survey area (Spearman rank correlation: $\mathrm{r}_{\mathrm{s}}=0.141, \mathrm{n}=19$, $\mathrm{p}=0.550$ ).

As true for Parexocoetus brachypterus larvae (Hunte et al. 1995), the surface water characteristics (salinity, temperature, $\mathrm{PO}_{4}-\mathrm{P}, \mathrm{NO}_{3}-\mathrm{NO}_{2}-\mathrm{N}$ ) were not significantly correlated with the abundance of the small juvenile size group or the large juvenile size group of $P$. brachypterus (Spearman rank correlation: for smaller juveniles, $\mathrm{r}_{\mathrm{s}}<0.390, \mathrm{p}>0.145$; for larger juveniles, $\mathrm{r}_{\mathrm{s}}<$ $0.406, \mathrm{p}>0.077$ in all cases). The abundance of adult $P$. brachypterus also showed no correlation with salinity, $\mathrm{PO}_{4}-\mathrm{P}$ or $\mathrm{NO}_{3}-\mathrm{NO}_{2}-\mathrm{N}$ (Spearman rank correlation: $\mathrm{r}_{\mathrm{s}}<$ $0.232, \mathrm{p}>0.324$ in all cases), but was correlated with temperature (Spearman rank correlation: $\mathrm{r}_{\mathrm{s}}=-0.642, \mathrm{n}$ $=20, p=0.005$ ). Moreover, in no case was the abundance of any size group significantly correlated with flotsam abundance taken by neuston tows (Hunte et al. 1995) at the same sampling stations (Spearman rank 
correlation: for smaller juveniles, $\mathrm{r}_{\mathrm{s}}=0.252, \mathrm{p}=0.272$; for larger juveniles, $r_{\mathrm{s}}=-0.270, \mathrm{p}=0.239$; for adults, $\mathrm{r}_{\mathrm{s}}=0.098, \mathrm{p}=0.670 ; \mathrm{n}=20$ in all cases). Finally, the abundance of neither larger juveniles nor adults was significantly correlated with moon phase (Spearman rank correlation: for larger juveniles, $r_{s}=-0.346, p=$ 0.132 ; for adults, $\mathrm{r}_{\mathrm{s}}=-0.070, \mathrm{p}=0.761 ; \mathrm{n}=20$ in both cases). However, as was the case with $P$. brachypterus larvae taken in neuston tows (Hunte et al. 1995), the abundance of smaller juveniles was higher with proximity to full moon (Spearman rank correlation: $r_{\mathrm{s}}=$ $0.610, \mathrm{n}=20, \mathrm{p}=0.008$ ).

\section{Exocoetus volitans}

A total of 670 specimens of Exocoetus volitans with a mean abundance of 8.38 fish per 40 min nightlighting was collected at the 20 stations over the survey area (Table 2). The length-frequency distribution was bimodal, the smaller size group having a mean length of $52.2 \mathrm{~mm} \mathrm{FL}$, and the larger size group $160.6 \mathrm{~mm}$ FL (Fig. 5). E. volitans reaches sexual maturity at about $140 \mathrm{~mm}$ (Bruun 1935). The larger size group is, therefore, referred to as adult and the smaller size group as juvenile in this study. However, adults represented $<3 \%$ of the total catch (Fig. 5), and were not analysed further.

Abundance of Exocoetus volitans juveniles varied significantly between stations (Table 3; Kruskal-Wallis test: $H=2.375, \mathrm{n}=80, \mathrm{p}<0.001$ ). There was no marked geographical pattern to the variation in abundance,

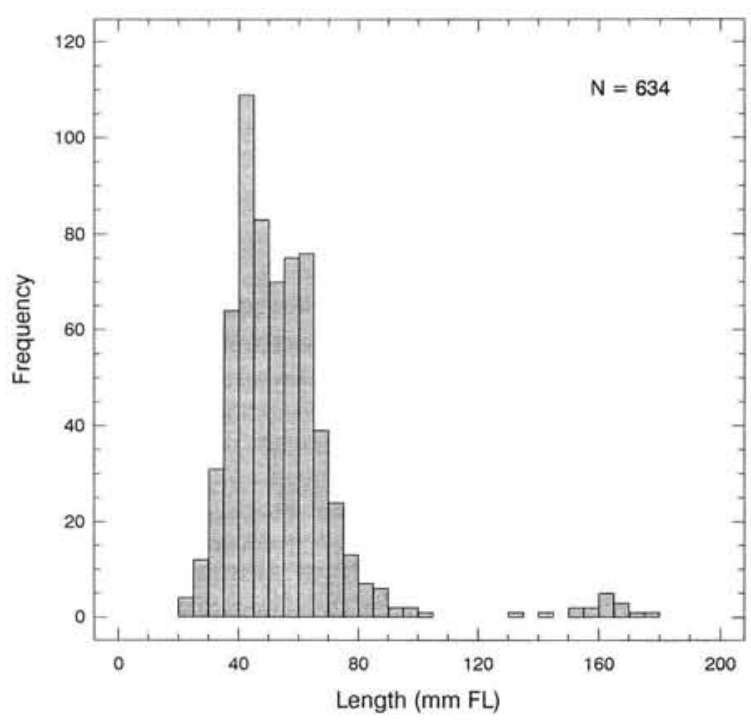

Fig. 5. Exocoetus volitans. Length distribution of juveniles collected by nightlighting and dipnetting across the survey area

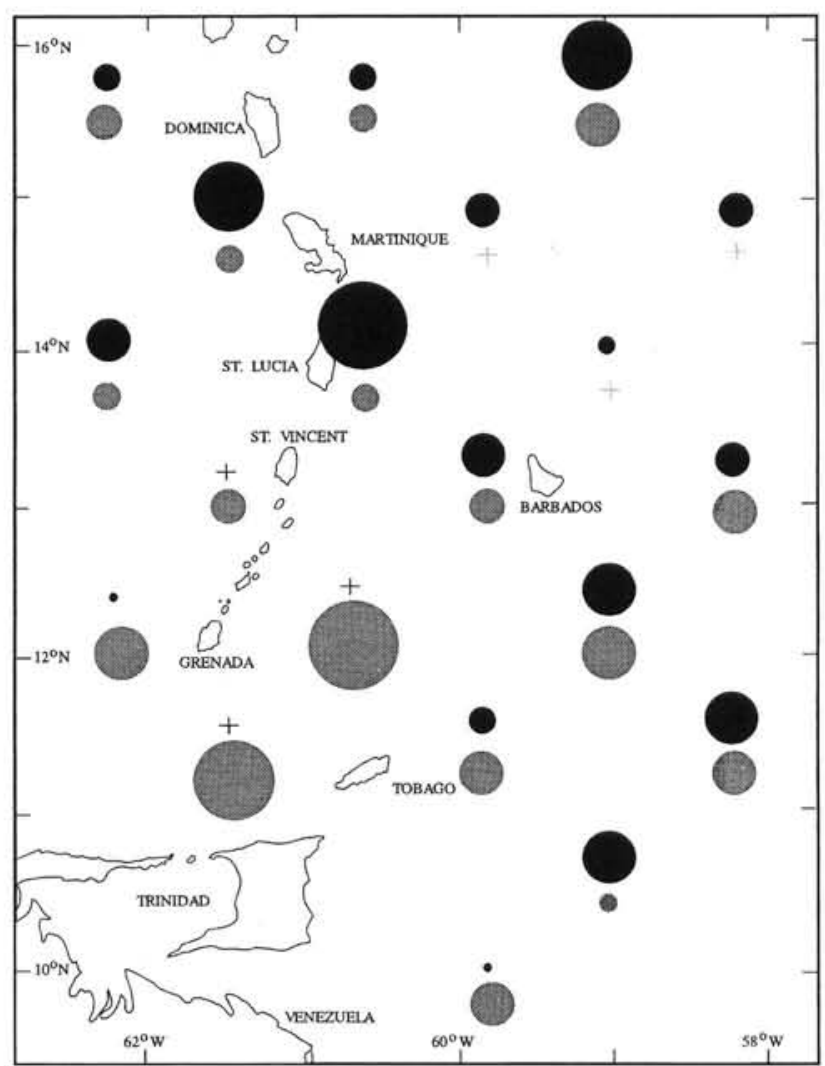

Fig. 6. Relative abundance of juveniles of (-) Exocoetus volitans and (๑) Hirundichthys affinis collected by nightlighting and dipnetting across the survey area. Area of circle is proportional to the mean abundance (range for E. volitans is 0 to 36.25 fish per $40 \mathrm{~min}$ nightlighting; range for $H$. affinis is 0 to 4.75 fish per $40 \mathrm{~min}$ nightlighting). $(+/+)$ station without $E$. volitans/H. affinis

although juveniles appeared to be least abundant in the southwest sector of the survey area (Fig. 6). Interestingly, variation in the abundance of $E$. volitans juveniles (mean length $52.2 \mathrm{~mm}$ FL) between stations was highly correlated with variation in abundance of $E$. volitans larvae taken in neuston tows (mean length $32.14 \mathrm{~mm}$ FL, Hunte et al. 1995; Spearman rank correlation: $r_{\mathrm{s}}=0.836, \mathrm{n}=20, \mathrm{p}<0.001$ ).

As true for Exocoetus volitans larvae (Hunte et al. 1995), none of the surface water characteristics (salinity, temperature, $\mathrm{PO}_{4}-\mathrm{P}, \mathrm{NO}_{3}-\mathrm{NO}_{2}-\mathrm{N}$ ) was significantly correlated with the abundance of $E$. volitans juveniles (Spearman rank correlation: $\mathrm{r}_{\mathrm{s}}<0.272, \mathrm{p}>0.309$ in all cases). Moreover, again as was the case for larvae, the abundance of $E$. volitans juveniles was not significantly correlated with either moon phase or flotsam abundance taken by neuston tows (Hunte et al. 1995) at the same sampling stations (Spearman rank correlation: for moon phase, $r_{s}=-0.228, p=0.210$; for flotsam, $r_{\mathrm{s}}=-0.061, \mathrm{p}=0.793 ; \mathrm{n}=20$ in both cases). 


\section{Hirundichthys affinis}

A total of 130 specimens of Hirundichthys affinis with a mean abundance of 1.63 fish per 40 min nightlighting was collected at the 20 stations over the survey area (Table 2). The length-frequency distribution was essentially bimodal, the smaller size group having a mean length of $63.7 \mathrm{~mm} \mathrm{FL}$, and the larger size group $203.1 \mathrm{~mm}$ FL (Fig. 7). H. affinis reaches sexual maturity at about $190 \mathrm{~mm}$ (Bruun 1935, Lewis et al. 1962). The larger size group is therefore referred to as adult and the smaller size group as juvenile in this study.

Abundance of both juveniles and adults of Hirundichthys affinis varied significantly between stations (Table 3; Kruskal-Wallis tests: for juveniles, $H=32.279$, $\mathrm{p}<0.02$; for adults, $H=42.633, \mathrm{p}=0.001 ; \mathrm{n}=80$ in both cases), but were not correlated with each other (Spearman rank correlation: $r_{s}=-0.124, n=20, p=0.589$ ). There was a tendency for the juveniles (mean length $63.7 \mathrm{~mm} \mathrm{FL}$ ) to be more abundant at southern than northern stations (Fig. 6). Interestingly, in spite of the small number of $H$. affinis adults taken by dipnetting (Fig. 7), variation in their abundance between stations was significantly correlated with variation in the abundance of $H$. affinis adults as detected by visual survey in the vicinity (within $25 \mathrm{nmi}$ ) of the sampling stations (Oxenford et al. 1995; Spearman rank correlation: $\mathrm{r}_{\mathrm{s}}=$ $0.563, \mathrm{n}=15, \mathrm{p}<0.03)$.

None of the surface water characteristics (salinity, temperature, $\mathrm{PO}_{4}-\mathrm{P}, \quad \mathrm{NO}_{3}-\mathrm{NO}_{2}-\mathrm{N}$ ) was significantly correlated with the abundance of Hirundichthys affinis juveniles (Spearman rank correlation: $r_{s}<0.369$, $p>$

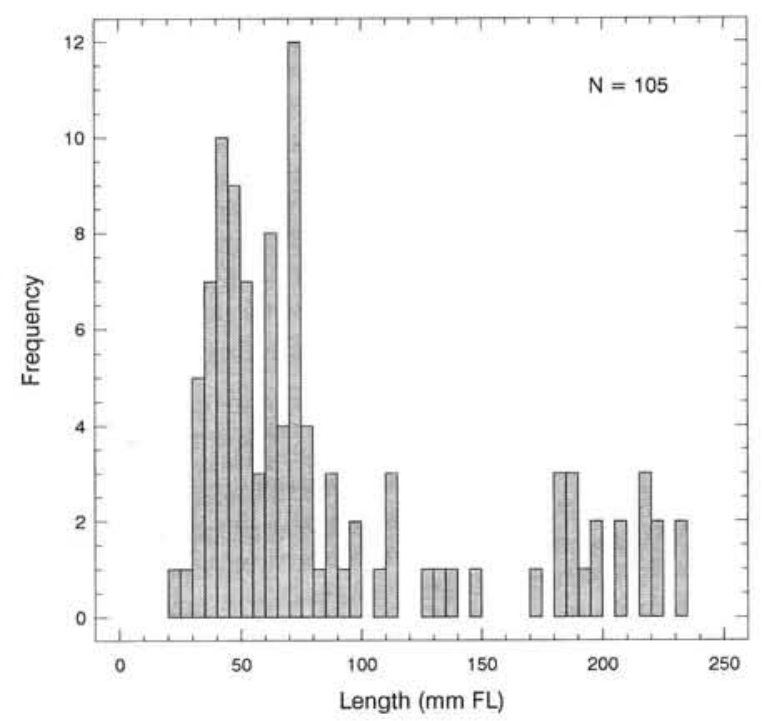

Fig. 7. Hirundichthys affinis. Length distribution of juveniles collected by nightlighting and dipnetting across the survey area
0.117 in all cases). Moreover, the abundance of $H$. affinis juveniles was not correlated with either moon phase or flotsam abundance taken by neuston tows (Hunte et al. 1995) at the same sampling stations (Spearman rank correlation: for moon phase, $\mathrm{r}_{\mathrm{s}}=0.285$, $\mathrm{p}=0.214 ;$ for flotsam, $\mathrm{r}_{\mathrm{s}}=-0.013, \mathrm{p}=0.955 ; \mathrm{n}=20$ in both cases).

\section{DISCUSSION}

Nightlighting and dipnetting has not previously been used to survey distribution and relative abundance of juvenile fish across the eastern Caribbean. Variation in catch rates of flyingfish between the 4 locations at each sampling station was low compared with variation between stations, suggesting that the method provides an adequate index of relative abundance between stations. Moreover, by changing locations at a station after each 40 min sampling period, there was no indication of a depletion effect that might have occurred through local over-sampling.

Twelve families of fish were collected during the survey and $73.5 \%$ of the individuals were flyingfish (Exocoetidae). Using a similar technique over a $1 \mathrm{yr}$ period off the northwest of Barbados, Lao (1989) collected 6 fish families, of which $89.8 \%$ of the individuals were flyingfish. These results suggest either that flyingfish are particularly common in surface waters of the eastern Caribbean by night, or that their phototactic behaviour makes them particularly susceptible to capture by nightlighting [see Gulland (1983) for discussion of inter-specific variation in phototactic behaviour of fish]. Parexocoetus brachypterus $(49.5 \%)$, Exocoetus volitans $(41.0 \%)$ and Hirundichthys affinis $(8.0 \%)$ accounted for $98.5 \%$ of the flyingfish catch in this study. Lao (1989) found that these 3 species in the same order of frequency accounted for $99.9 \%$ of the flyingfish he captured off Barbados during April and May 1988 , the same months as the survey in this study. Given the possibility of different responses to surface illumination, these interspecific differences in catch rates do not necessarily reflect differences in absolute abundance. Nevertheless, the high catch rates for flyingfish observed in this study confirm the feasibility of using nightlighting and dipnetting as a large-scale survey tool for juvenile flyingfish.

The length-frequency distribution of Parexocoetus brachypterus in this study was trimodal, a pattern also reported by Lao (1989) for the same species off Barbados. The largest size group was adult, and the simultaneous occurrence of 2 small size groups may indicate 2 pulses of annual spawning in $P$. brachypterus. This would reconcile the observations of Lewis (1961) and Khokiattiwong (1988) on spawning of $P$. brachypterus 
off Barbados, the former suggesting that peak spawning occurs between September and January, the latter suggesting it occurs between March and August.

The length-frequency distribution of Hirundichthys affinis was bimodal, the larger size group being adult. Lao (1989) reported a similar distribution for $H$. affinis off Barbados. These results, and the monthly modal progression of size groups observed by Lao (1989), strongly suggest that $H$. affinis, the species on which the eastern Caribbean fishery is based, is an annual species. This observation has important implications for approaches to assessment and management of $H$. affinis in the Caribbean.

The length-frequency distribution of Exocoetus volitans was bimodal. The larger size group was adult, but accounted for $<3 \%$ of the catch. Lao (1989) reported that $98 \%$ of his nightlighting catch of $E$. volitans was juvenile. The virtual absence of adults of $E$. volitans is consistent with their negligible numbers observed during visual surveys in the eastern Caribbean (Oxenford et al. 1995) and with their scarcity in both commercial flyingfish catches in the Caribbean (Storey 1983) and in experimental gillnet catches of flyingfish off Barbados (Khokiattiwong 1988).

An interesting characteristic of flyingfish distribution in the eastern Caribbean is the tendency for geographical partitioning both interspecifically and intraspecifically by life history stage. For example, as adults (Oxenford et al. 1995) Exocoetus volitans was virtually absent from the survey area, supporting previous suggestions that $E$. volitans is essentially oceanic and spawns in the Atlantic (primarily between October and April; Grudtsev et al. 1987), Cypselurus cyanopterus was largely restricted to the northeast sector of our survey area, and Hirundichthys affinis and Parexocoetus brachypterus were abundant to the west (lee) of the Lesser Antilles islands and in the southeast of the survey area, i.e. east of Barbados and Tobago [note that $H$. affinis and $P$. brachypterus adults may partition their environment vertically; Shiokawa (1969), Gorelova (1980) and Nesterov \& Bazanov (1986) suggest that $H$. affinis is distributed deeper than $P$. brachypterus]. As larvae (Hunte et al. 1995) and small juveniles (this paper), E. volitans was less abundant close to islands and was particularly rare in the southwest sector of the survey area near the South American mainland. By contrast, larvae (Hunte et al. 1995) and small juveniles (this paper) of $P$. brachypterus were more abundant close to islands, and were particularly common in the southwest and rare in the northeast of the survey area. C. cyanopterus larvae were largely restricted to the north of the survey area, and were rare in the southwest (Hunte et al. 1995).

In the context of intraspecific separation by life history stage, our data strongly suggest that different life history stages of flyingfish species can have markedly different geographical distributions. This was particularly evident for Exocoetus volitans, with adults (Oxenford et al. 1995) being largely absent from our survey area, but larvae (Hunte et al. 1995) and juveniles (this paper) being common components of our neuston tows and nightlighting catches. However, it was also observed for other flyingfish species. For example, variation in abundance of juveniles and adults of Hirundichthys affinis was not significantly correlated across the survey area, and the same was true for small juveniles and adults of Parexocoetus brachypterus. However, the abundance of large juveniles of $P$. brachypterus was significantly correlated with that of adults, indicating the re-ordering of distributional patterns that must occur as one life history stage grows into the next.

The fact that different life history stages of a given flyingfish species may have different and discrete geographical distributions is supported by the observations that the different survey methods often detected similar life history stages as having the same geographical distribution. For example, variation in abundance of Parexocoetus brachypterus larvae taken by neuston tows was significantly correlated across the survey area with variation in abundance of the smaller size group of $P$. brachypterus juveniles sampled by nightlighting. Similarly, variation in abundance of Exocoetus volitans larvae taken by neuston tows was significantly correlated across the survey area with variation in abundance of $E$. volitans juveniles sampled by nightlighting. Finally, variation in abundance of Hirundichthys affinis adults, as detected by visual survey across the survey area, was significantly correlated with variation in abundance of adults sampled by nightlighting. These observations not only confirm the integrity of the patterns of geographical distribution observed, but also indicate that the various methods used to survey flyingfish, namely visual surveys for adults (Oxenford et al. 1995), neuston tows for larvae (Hunte et al. 1995) and nightlighting (this study), are reliable tools for assessing the distribution and relative abundance of flyingfish on a regional scale.

Acknowledgements. This study was funded by IDRC (International Development Research Centre, Ottawa, Canada) as a component of the Eastern Caribbean Flyingfish Project. The many organisations and individuals who made contributions have been acknowledged in Paper I of this 3 part series.

\section{LITERATURE CITED}

Breder, C. M. (1938). A contribution to the life histories of Atlantic Ocean flyingfish. Bull. Bingham Oceanogr. Coll. 6: $1-126$

Bruun, A. F. (1935). Flying-fish (Exocoetidae) of the Atlantic: systematic and biological studies. Dana Rep. 6: 1-106 
Evans, J. W. (1961). Normal stages of the early development of the flyingfish, Hirundichthys affinis (Günther). Bull. mar. Sci. 11: 483-502

Gorelova, T. A. (1980). The feeding of young flyingfishes of the family Exocoetidae and of the smallwing flyingfish, Oxyporhamphus micropterus, of the family Hemirhamphidae. J. Ichthyol. 20: 60-71

Gulland, J. A. (1983). Fish stock assessment: a manual of basic methods. Wiley and Sons, New York

Grudtsev, M. E., Salekhova, L. P., Lushchina, V. G. (1987). Distribution, ecology and intraspecific variability of flyingfishes of the genus Exocoetus of the Atlantic Ocean. J. Ichthyol. 27: 39-50

Hunte, W., Oxenford, H. A., Mahon, R. (1995). Distribution and abundance of flyingfish (Exocoetidae) in the eastern Caribbean. II. Spawning substrata, eggs and larvae. Mar. Ecol. Prog. Ser. 117: 25-37

Imai, S. (1959). Studies on the life histories of the flyingfishes found in the adjacent waters of Japan. I. Mem. Fac. Fish. Kagoshima Univ. 7: 1-85 (English summary)

Imai, S. (1960). Studies on the life histories of the flyingfishes found in the adjacent waters of Japan. II. Mem. Fac. Fish. Kagoshima Univ. 8: 8-45 (English summary)

Khokiattiwong, S. (1988). Seasonality and abundance of Hirundichthys affinis and Parexocoetus brachypterus. M.Sc. thesis, McGill University, Montreal

Kovalevskaya, N. V. (1964). Study of development of the 'twowinged' flyingfishes of the genus Exocoetus (Exocoetidae, Pisces). Tr. Inst. Okeanol. Akad. Nauk. SSSR 73: 204-223 (English summary)

Lao, M. R. (1989). Distribution and abundance of flotsam, larval fish and juvenile fish off Barbados with particular

This article was submitted to the editor reference to the Exocoetidae. M.Sc. thesis, McGill University, Montreal

Lewis, J. B. (1961). The growth, breeding cycle and food of the flyingfish Parexocoetus brachypterus hillianus (Gosse). Bull. mar. Sci. 11: 258-266

Lewis, J. B., Brundritt, J. K., Fish, A. G. (1962). The biology of the flyingfish Hirundichthys affinis (Günther). Bull. mar. Sci. Gulf Caribb. 12: 73-94

Mahon, R., Oxenford, H., Hunte, W. (eds.) (1986). Development strategies for flyingfish fisheries of the eastern Caribbean, Workshop proceedings, IDRC-MR128e. International Development Research Centre, Ottawa

Nesterov, A. A., Bazanov, S. I. (1986). Vertical distribution and behaviour of flyingfish (Exocoetidae). J. Ichthyol. 26: 159-162

Oxenford, H. A., Mahon, R., Hunte, W. (eds.) (1993). The Eastern Caribbean Flyingfish Project. Organisation of Eastern Caribbean states (OECS) Fishery Report 9, St. Vincent

Oxenford, H. A., Mahon, R., Hunte, W. (1995). Distribution and relative abundance of flyingfish (Exocoetidae) in the eastern Caribbean. I. Adults. Mar. Ecol. Prog. Ser. 117: $11-23$

Shiokawa, T. (1969). Study of the swimming habits of flying fish in the spawning season. Proceedings of FAO Conference on fish behaviour in relation to fishing technique and tactics, Bergen, Norway, 19-27th Oct., 1967, Vol. 3. FAO Fish. Rep. 62: 579-589

Storey, K. W. (1983). Aspects of the biology and fishery of the flyingfish, Hirundichthys affinis, at Barbados. M.Phil. thesis, University of the West Indies, Barbados

Zar, J. H. (1984). Biostatistical analysis. Prentice-Hall, Englewood Cliffs, NJ

Manuscript first received: March 8, 1994

Revised version accepted: October 4, 1994 